\title{
Knowledge about missed contraceptive pills among married women at King Abdulaziz University Hospital
}

This article was published in the following Dove Press journal:

Patient Preference and Adherence

10 March 2015

Number of times this article has been viewed

\author{
Rahila Iftikhar \\ Bahaa Abdulrahman \\ Aba Al Khail \\ Family and Community Medicine \\ Department, King Abdulaziz \\ University Hospital, Jeddah, \\ Saudi Arabia
}

Correspondence: Rahila Iftikhar Family and Community Medicine Department, King Abdulaziz University Hospital, PO Box 42806, Jeddah 2I55I, Saudi Arabia

Tel +96626402II4

Email rahila_iftikhar@hotmail.com
Background: Oral contraceptive pills (OCPs) are one of the most reliable methods of contraception. However, lack of knowledge about oral contraceptive use and inconsistent pilltaking might result in decreased efficacy. The study reported here aimed to explore women's knowledge about oral contraceptive use and assess the factors associated with knowledge about OCPs among users.

Methods: This cross-sectional survey was conducted at King Abdulaziz University Hospital, Jeddah, Saudi Arabia between April and June 2014. We included married, non-pregnant women $>18$ years old who had used a combined 21-day OCP for at least 3 months prior to recruitment. A questionnaire was used to collect the participants' demographic information. It also assessed their knowledge about OCPs. Data were entered into and analyzed using SPSS software.

Results: A total of 357 women were recruited. Of these, $57.7 \%$ reported they knew what to do after missing one or two pills, but only $18.3 \%$ knew exactly what to do after missing more than two pills consecutively. Postgraduate women had a significantly higher knowledge score than illiterate women $(P=0.002)$ and those who had completed at least primary education $(P=0.001)$. Conversely, there was no difference in knowledge scores between Saudi and expatriate women $(P=0.2)$. Monthly incomes $(P=0.2)$ and mode of OCP selection $(P=0.2)$ were also not significantly associated with knowledge scores.

Conclusion: Women had poor knowledge about OCP use. Appropriate measures should be taken to educate women about proper oral contraceptive use.

Keywords: oral contraception, oral contraceptive, Saudi Arabia, OCP

\section{Background}

Oral contraceptives are the most widely used method of contraception because of their accessibility and reversibility. ${ }^{1}$ Unfortunately, their efficacy is limited by problems related to compliance with prescribed regimens, which is in turn related to knowledge about correct usage and the occurrence of adverse events. Failure rates of less than $1 \%$ have been reported in women who use oral contraceptive pills (OCPs) effectively, with rates as high as $9 \%$ in those who do not use pills consistently or correctly.,

While there is a paucity of data regarding contraceptive use in Saudi Arabia, and data from studies conducted abroad cannot reflect the tendencies in the Saudi population. Some women do not use OCPs because of their incorrect perceptions regarding their utilization. ${ }^{4}$ Secondly, the medications that are used for emergency contraception are available through Gynecologist prescription in Saudi Arabia. ${ }^{5}$ OCPs are among the most frequent form of contraception in Saudi Arabia as well as in other Arab countries 
such as Jordan and Iran, where an estimated 18.4\%-36.6\% of women are reported to use the pill. ${ }^{6-8}$

In the Middle East and North African (MENA) countries, an estimated $15 \%-58 \%$ of pregnancies are unintended. Women with unintended pregnancies may resort to abortion, and consequently increase their health risk, especially when the procedure is performed in an unsanitary setting or by unskilled medical personnel. In particular, women in MENA countries have an increased risk because abortion is forbidden or restricted in these areas. Unfortunately, unintended pregnancies are also an issue among women who use oral contraceptives. ${ }^{5,9}$ One report by Alsibiani ${ }^{5}$ that investigated misoprostol use as a self-administered medical abortifacient among Saudi women showed that $39.7 \%$ of the respondents used OCPs.

In Saudi Arabia, OCPs are available over-the-counter without prescription, and a pharmacist's advice might sometimes be a user's only source of information. ${ }^{10,11}$ Self-medication may result in inappropriate use of pills and consequently poor efficacy. However, women tend to start contraception on their own because of high fertility rates, less accessibility to health care for women, and large families. In one report, ${ }^{12}$ it was found that $28.7 \%$ of Saudi women used an OCP for contraception. Most of the women lacked knowledge about OCPs and had a negative attitude toward their use. Although over threequarters of the women had some knowledge about what to do if they missed a pill, less than $10 \%$ knew exactly what to do. Thus, in Saudi Arabia there are gaps in the knowledge and practices of women using OCPs for birth control. If large gaps in knowledge about OCP use are identified among users, recommendations can be made for health care providers to provide contraceptive counseling to all women.

The study therefore aimed to explore the knowledge and practices of women regarding oral contraceptive utilization and to assess the factors associated with knowledge about their use. We hypothesized that women have inadequate knowledge about oral contraceptive use and they do not understand missed-pill instructions.

\section{Methods}

\section{Design and setting}

This was a cross-sectional survey conducted between April 2014 and June 2014 at the outpatient departments of General Practice, Internal Medicine, Surgery, Gynecology, and the Well-baby Clinics of King Abdulaziz University Hospital in Jeddah, Saudi Arabia.

\section{Participants}

After obtaining approval from the University of King Abdulaziz Institutional Ethical Committe, we invited married, non-pregnant women $>18$ years old who had used a combined 21-day OCP during the previous 3 months to participate in this survey. Women who did not consent to participate and those who had come for contraceptive advice were excluded from the study.

\section{Sample determination and data-collection procedure}

In a previous study conducted in Saudi Arabia, it was observed that $36.6 \%$ of women had good knowledge about the use of OCPs. Therefore, as per the World Health Organization's manual of sample-size determination in health sciences, ${ }^{13}$ for a margin of error of $5 \%$ and assuming a confidence interval of $95 \%$, the required sample size was $357 . .^{12}$

Convenient non-probability sampling was done, and questionnaires were administered consecutively to participants, who were interviewed by female medical students in a private room. A total of 500 questionnaires were sent out for distribution. Of these, 357 were completed, giving a response rate of $71.4 \%$. Most of the nonresponders did not want to discuss issues related to OCP.

Prior to the interview, all the students were lectured about oral contraception and the World Health Organization guidelines on oral contraceptive use. During interviews, the medical students used questionnaires to collect sociodemographic data from survey participants. The questions also assessed the participants' knowledge about oral contraceptive use.

The level of knowledge was categorized as poor (inadequate), average (some knowledge), or good (satisfactory) on a scale of $0-10$. Women who had scores ranging from 0 to 4 had poor knowledge. Respondents with scores ranging from 5 to 7 and 8 to 10 had average and good knowledge, respectively.

\section{Instrument}

The survey instrument was derived from the World Health Organization's family-planning handbook for providers. ${ }^{14}$ The questionnaire comprised 30 questions, which were translated into Arabic, in five sections: (1) five items that elicited the personal data of the women, (2) five questions on obstetric history, (3) five questions on choice of familyplanning method, (4) five questions on knowledge about starting the pill, and (5) ten questions on knowledge about OCP 
use. The questionnaire is presented in the "Supplementary material" section of this paper.

\section{Data analysis}

The data were entered into and analyzed using SPSS software (v 20; IBM Corp, Armonk, NY, USA). Frequencies and proportions were computed for categorical variables, while means were calculated for continuous variables. An independent sample $t$-test was used to compare differences between continuous variables; the chi-square test was used to determine associations between categorical variables. The chi-square and Fischer's exact tests were used if the cell counts were $<5$. Statistical significance was set at the 0.05 probability level. Results are expressed as frequency (percent) and as mean \pm standard deviation (SD).

\section{Results}

A total of 357 women aged $32.60 \pm 6.82$ years completed the questionnaire. Over half of the women were Saudi, and close to half of the women in the sample were 26-35 years old (Table 1). In most cases, participants had either completed secondary or high school. More than $80 \%$ of the women were housewives and had a monthly household income of $\leq 10,000$ Saudi riyals (SAR).

The average number of pregnancies, including miscarriages/abortions, was 4.30 \pm 2.62 . Most of the women (94.4\%) had children; the estimated number of children per woman was $3.50 \pm 2.17$. The average number of years of OCP use was $3.3 \pm 3.7$ years, and women reported missing a pill $1.30 \pm 1.58$ times per month.

As shown in Table 2, oral contraception was advised by a gynecologist in over half of the women, whereas approximately $24 \%$ of the respondents reported initiating OCP. Most respondents (79.9\%) had read instructions in package inserts, and more than half agreed that they had fair knowledge about the use of OCPs. A large proportion (86.7\%) of the respondents also reported using OCPs regularly.

Close to $60 \%$ of the respondents correctly responded that OCPs were one of the most reliable methods of contraception available in Saudi Arabia (Table 3). However, few women $(20.4 \%)$ had correct knowledge about what to do in case they vomited within 2 hours of taking contraceptive pills. Similarly, less than $30 \%$ of the participants responded correctly that OCPs could be started on any day of the cycle if pregnancy was ruled out. Less than $15 \%$ of the women answered correctly that additional contraception was warranted when the OCP was initiated after the 5th day of the cycle, and close to half of the participants gave an incorrect
Table I Sociodemographic characteristics of the participants

\begin{tabular}{|c|c|c|}
\hline Variable & Frequency $(n=357) *$ & Percent \\
\hline \multicolumn{3}{|l|}{ Age, years } \\
\hline$\leq 25$ & 51 & 14.3 \\
\hline $26-35$ & 185 & 51.8 \\
\hline $36-45$ & 110 & 30.8 \\
\hline$>45$ & 11 & 3.1 \\
\hline \multicolumn{3}{|l|}{ Nationality } \\
\hline Saudi & 206 & 57.7 \\
\hline Non-Saudi & 27 & 7.6 \\
\hline \multicolumn{3}{|l|}{ Education } \\
\hline None & 22 & 6.2 \\
\hline Primary school & 34 & 9.5 \\
\hline Secondary & 55 & 15.4 \\
\hline High school & 134 & 37.5 \\
\hline University graduate & 94 & 26.3 \\
\hline Postgraduate & 18 & 5.0 \\
\hline \multicolumn{3}{|l|}{ Occupation } \\
\hline Housewife & 287 & 80.4 \\
\hline Teacher & 20 & 5.6 \\
\hline Nurse & 6 & 1.7 \\
\hline Office job & 21 & 5.9 \\
\hline Self-employed & 9 & 2.5 \\
\hline Student & 13 & 3.6 \\
\hline Engineer & I & 0.3 \\
\hline \multicolumn{3}{|l|}{ Income, SAR (USD) } \\
\hline$<5,000(1,333)$ & 162 & 45.4 \\
\hline $5,000-10,000(1,333-2,666)$ & 133 & 37.3 \\
\hline $10,000-15,000(2,666-3,999)$ & 45 & 12.6 \\
\hline $15,000-20,000(3,999-5,333)$ & 11 & 3.1 \\
\hline$>20,000(5,333)$ & 6 & 1.7 \\
\hline \multicolumn{3}{|l|}{ Ever been pregnant } \\
\hline Yes & 337 & 94.4 \\
\hline No & 20 & 5.6 \\
\hline \multicolumn{3}{|l|}{ Have children } \\
\hline Yes & 337 & 94.4 \\
\hline No & 19 & 5.3 \\
\hline
\end{tabular}

Note: $*$ The total might be $<357$ in cases where respondents failed or declined to respond.

Abbreviation: SAR, Saudi riyals; USD, United States dollars.

response or did not know what to expect before starting a new pack of OCPs.

Regarding missed pills, $64.5 \%$ of the participants were knowledgeable about what to do if they missed one or two pills. Furthermore, in case of three or more missed pills, $72.8 \%$ knew that they had to take the last pill as soon as possible while $69.7 \%$ knew that they had to continue taking the rest of the pack as prescribed. On the contrary, only about $15 \%$ knew that they had to use an additional method of contraception for the next 7 days, while approximately $16 \%$ knew that if the pills were missed in the 3rd week, they had to start a new pack after finishing the previous one without waiting for the 7-day pill-free interval.

Figure 1 shows that a large proportion of the women $(n=228 ; 63.9 \%)$ had inadequate knowledge (score of $0-4)$ 
Table 2 Initiation of oral contraception and the participants' attitudes and habits regarding its use

\begin{tabular}{|c|c|c|}
\hline Characteristic & $\begin{array}{l}\text { Frequency } \\
(\mathrm{n}=357)^{*}\end{array}$ & Percent \\
\hline \multicolumn{3}{|l|}{ Selection of OCP for contraception } \\
\hline Advised by a general physician & 30 & 8.4 \\
\hline Advised by a gynecologist & 224 & 63.1 \\
\hline Others & 97 & 27.2 \\
\hline Cannot remember & 4 & I.I \\
\hline \multicolumn{3}{|c|}{ Received instructions from a physician on use of the OCP } \\
\hline Yes & 236 & 66.7 \\
\hline No & 63 & 17.8 \\
\hline Not sure & 13 & 3.7 \\
\hline OCP not prescribed by a doctor & 42 & 11.9 \\
\hline \multicolumn{3}{|l|}{ Read instructions in package insert } \\
\hline Yes & 283 & 79.9 \\
\hline No & 71 & 20.1 \\
\hline \multicolumn{3}{|l|}{ Perceived knowledge about OCP } \\
\hline Strongly agree & 70 & 19.8 \\
\hline Agree & 106 & 29.9 \\
\hline Somewhat agree & 105 & 29.7 \\
\hline Not sure & 61 & 17.2 \\
\hline Not at all & 12 & 3.4 \\
\hline \multicolumn{3}{|l|}{ Do you use OCPs as recommended? } \\
\hline Yes & 307 & 86.7 \\
\hline No & 47 & 13.3 \\
\hline \multicolumn{3}{|c|}{ Do you know what should be done if you forget one or two pills? } \\
\hline Yes & 199 & 57.7 \\
\hline No & 85 & 24.6 \\
\hline Not sure & 61 & 17.7 \\
\hline \multicolumn{3}{|c|}{$\begin{array}{l}\text { Do you know what should be done if you forget three or more pills } \\
\text { in a row? }\end{array}$} \\
\hline Yes & 63 & 18.3 \\
\hline No & 171 & 49.6 \\
\hline Not sure & 111 & 32.2 \\
\hline
\end{tabular}

Note: $*$ The total might be $<357$ in cases where respondents failed or declined to respond.

Abbreviation: OCP, oral contraceptive pill.

about OCP use. Only 2.2\% had satisfactory knowledge (score of 8-10). Women were most likely to have satisfactory knowledge about what do after missing one to two pills $(P<0.001)$. A relatively higher proportion of women with a higher educational attainment $(50.0 \%)$, lower income $(50.0 \%)$, previous pregnancy $(75.0 \%)$, and history of OCP use $(100.0 \%)$ had higher knowledge scores. Women who were prescribed OCPs by a gynecologist or who selfinitiated OCPs (37.5\% in both cases) and those who received instructions from a physician $(50.0 \%)$ or read instructions on package inserts $(50.0 \%)$ also had higher knowledge scores (Table 4). Further analysis using analysis of variance showed that postgraduate women had a significantly higher knowledge score than illiterate women $(P=0.002)$ and those who had completed at least primary education $(P=0.001)$.
Conversely, there was no difference in knowledge scores among Saudi and expatriate women $(P=0.2)$. Similarly, monthly incomes $(P=0.2)$ and mode of OCP selection $(P=0.2)$ were not significantly associated with knowledge scores.

\section{Discussion}

In order to determine the knowledge and practices pertaining to oral contraceptive use among women at a tertiary health care center in Jeddah, Saudi Arabia, we identified the demographic status of the participants, the characteristics of OCP users, and their perceived knowledge about initiating and using OCPs. Although a similar study had been conducted in Riyadh, Saudi Arabia, ${ }^{9}$ the authors did not assess the women's understanding of OCP instructions related to missed pills or their knowledge about withdrawal bleeding during oral contraceptive use.

Over half of the women in this study had completed either high school or secondary education. Further, we found that women who had a higher educational attainment were more likely to have satisfactory knowledge about OCPs. This finding is consistent with those of other authors who found that women's knowledge of and attitudes toward contraception were associated with their level of education. ${ }^{9,15}$

We found that women missed a pill on average $1.30 \pm 1.58$ times per month. While we did not investigate the reasons for missed pills in our study, it is plausible that women missed one or more pills in a cycle because they did not take their pills at the same time each day, they did not fully understand the instructions in package inserts, or they had received insufficient information or help from their health care provider. A recent study by Frost et al demonstrated that every year only $50 \%$ of the women at risk of unintended pregnancy used OCPs consistently and correctly. ${ }^{16}$ In addition, they found that $27 \%$ of women had a higher risk of unintended pregnancy owing to inconsistent or incorrect use of OCPs. Another 15\% were at high risk because of gaps in contraceptive use caused by various factors, including difficulty in using or accessing methods, infrequent sexual intercourse, or poor perceptions of risk for pregnancy. ${ }^{16}$ According to other authors, ${ }^{17}$ being a new user or having had a previous unintended pregnancy was associated with inconsistent use.

In this study, oral contraceptive was initiated by a gynecologist in $63.1 \%$ of the women. This finding is consistent with earlier reports from Saudi Arabia, which found that OCPs were initiated by a gynecologist in most cases. ${ }^{6,9}$ Al-Turki ${ }^{6}$ reported that in $64.5 \%$ of the cases, oral contraceptives were initiated by physicians. In the West, 
Table 3 Participants' responses to questions that assessed missed pills*

\begin{tabular}{|c|c|c|c|c|}
\hline Assessment questions & Correct & Incorrect & Don't know & Total $(\mathbf{N}=\mathbf{3 5 7})$ \\
\hline $\begin{array}{l}\text { I. The oral contraceptive pill is one of the most reliable } \\
\text { contraceptive methods. }\end{array}$ & $204(57.6)$ & $115(32.5)$ & $35(9.9)$ & 354 \\
\hline $\begin{array}{l}\text { 2. In case of vomiting within } 2 \text { hours of taking OCP, another pill } \\
\text { should be taken as soon as possible. }\end{array}$ & $72(20.4)$ & $216(61.2)$ & $65(18.4)$ & 353 \\
\hline $\begin{array}{l}\text { 3. OCP can be started any day of the cycle if the woman is sure } \\
\text { that she is not pregnant. }\end{array}$ & $96(27.2)$ & $228(64.6)$ & $29(8.2)$ & 353 \\
\hline $\begin{array}{l}\text { 4. Additional contraception is required when oral contraceptive } \\
\text { pill is started after the } 5 \text { th day of the cycle. }\end{array}$ & $50(14.1)$ & $26 \mid(73.7)$ & $43(12.1)$ & 354 \\
\hline 5. You must wait for withdrawal bleeding to start the new pack. & $175(49.4)$ & $158(44.6)$ & $21(5.9)$ & 354 \\
\hline 6. What should be done if you forget one to two pills? & $220(64.5)$ & 57 (16.7) & 64 (18.8) & 341 \\
\hline \multicolumn{5}{|l|}{ What should you do if you forget three or more pills? } \\
\hline I. Take the last pill you missed as soon as you remember. & $227(72.8)$ & $43(13.8)$ & $42(13.5)$ & 312 \\
\hline 2. Continue taking the rest of the pack as usual. & $216(69.7)$ & $50(16.1)$ & $44(\mid 4.2)$ & 310 \\
\hline 3. Use an additional method of contraception for the next 7 days. & $46(15.3)$ & $193(64.3)$ & $61(20.3)$ & 300 \\
\hline $\begin{array}{l}\text { 4. If three or more pills are missed in the } 3 r d \text { week, a new } \\
\text { pack should be started after finishing the pack without a 7-day } \\
\text { pill-free interval. }\end{array}$ & $48(16.2)$ & $77(26.0)$ & I7I (57.8) & \\
\hline
\end{tabular}

Notes: *Data are presented as frequency and frequency (percent). The total in each row may not add up to $100 \%$, as some respondents failed or declined to respond to a question.

Abbreviation: OCP, oral contraceptive pill.

it was reported that $78 \%$ of Planned Parenthood clinics offered quick-start pill initiation, as did $47 \%$ of publichealth departments. ${ }^{18}$ However, the authors found that $38 \%$ of obstetricians and gynecologists, $27 \%$ of other public clinics, and $13 \%$ of family physicians initiated OCPs in their patients. ${ }^{18}$

Although most women in our study were advised by a gynecologist, they had inadequate knowledge about OCPs. This underscores a lack of patient education by physicians. While we did not assess the quality of patient education provided by physicians, it is possible that other factors, including the patient's understanding of instructions,

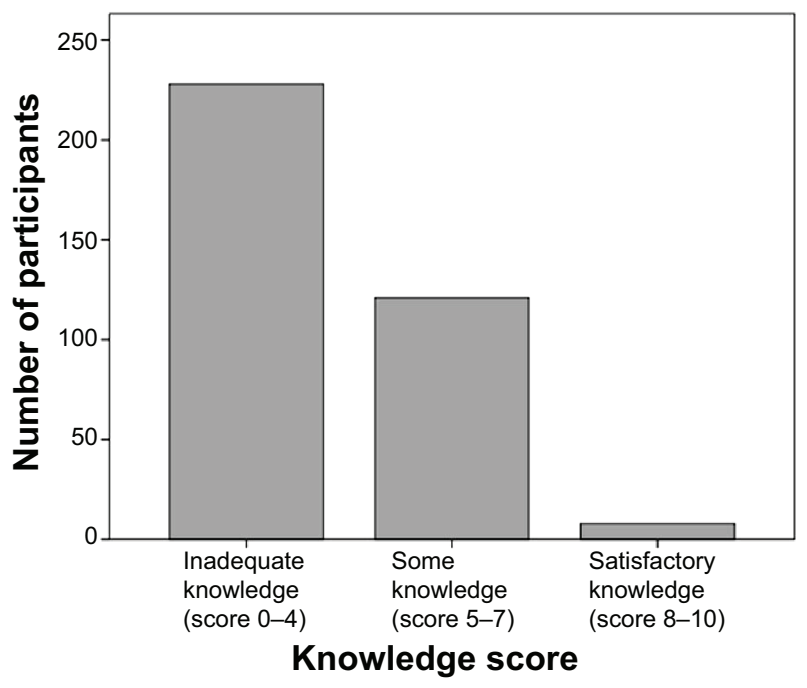

Figure I Participants' knowledge scores on oral contraceptive use. memory, and level of education may influence knowledge scores. Besides, women may be well educated at the time of initial prescription but they may not be followed up for a long period or receive incorrect information from other sources.

In this study, $79.7 \%$ of the women who participated because they wished to be assessed for their knowledge on OCPs had read the instructions in OCP package inserts, and more than half of the participants agreed that they had fair knowledge about oral contraceptive use. Unfortunately, these women had inadequate knowledge about OCPs, and their misconstrued perception may put them at high risk of experiencing an unintended pregnancy. Difficulties in understanding missed-pill instructions contained in package inserts have been reported in a recent systematic review. ${ }^{19}$ In that report, the authors suggested that providing written brochures with information on missed-pill instructions may improve women's knowledge of how to manage missed pills. Furthermore, they suggested that graphic-based missed-pill instructions and those that did not include extensive information may help improve comprehension.

Ten questions in our study assessed women's perceived knowledge about initiating and using OCPs. Although $57.7 \%$ of the respondents believed they knew what to do if they forgot one or two pills, $64.5 \%$ gave the correct answer about the measure to undertake in such a situation. We found that perceived knowledge about missing one to two pills per cycle was associated with a good score. Earlier studies from Saudi Arabia ${ }^{9}, 12$ showed similar results. In one study, ${ }^{9} 79 \%$ 
Table 4 Association of sociodemographic characteristics with knowledge score*

\begin{tabular}{|c|c|c|c|}
\hline Variable & Inadequate knowledge (0-4) & Some knowledge (5-7) & Satisfactory knowledge $(8-10)$ \\
\hline \multicolumn{4}{|l|}{ Income, SAR (USD) } \\
\hline$<5,000(1,333)$ & $112(49.1)$ & $46(38.0)$ & $4(50.0)$ \\
\hline $5,000-10,000(1,333-2,666)$ & $81(35.5)$ & $50(4 \mid .3)$ & $2(25.0)$ \\
\hline $10,000-15,000(2,666-3,999)$ & $24(10.5)$ & $20(16.5)$ & I (I2.5) \\
\hline $15,000-20,000(3,999-5,333)$ & $7(3.1)$ & $3(2.5)$ & I (I2.5) \\
\hline$>20,000(5,333)$ & $4(1.8)$ & $2(1.7)$ & $0(0.0)$ \\
\hline \multicolumn{4}{|l|}{ Mode of OCP selection } \\
\hline General physician & I8 (8.0) & II (9.I) & I (I2.5) \\
\hline Gynecologist & $145(64.2)$ & $76(62.8)$ & $3(37.5)$ \\
\hline Self-prescribed & $52(33.0)$ & $29(34.0)$ & $3(37.5)$ \\
\hline Others & $7(3.1)$ & $5(4.1)$ & I (I2.5) \\
\hline Cannot remember & $4(1.8)$ & $0(0.0)$ & $0(0.0)$ \\
\hline \multicolumn{4}{|l|}{ Previous pregnancy } \\
\hline Yes & $216(94.7)$ & II 5 (95.0) & $6(75.0)$ \\
\hline No & $12(5.3)$ & $6(5.0)$ & $2(25.0)$ \\
\hline \multicolumn{4}{|c|}{ Instructions by doctor regarding OCP use } \\
\hline Yes & $149(65.9)$ & $83(69.2)$ & $4(50.0)$ \\
\hline No & $44(19.5)$ & $16(13.3)$ & $3(37.5)$ \\
\hline Not sure & $9(4.0)$ & $4(3.0)$ & $0(0.0)$ \\
\hline Not prescribed by doctor & $24(10.6)$ & $17(14.2)$ & I (I2.5) \\
\hline \multicolumn{4}{|c|}{ Instructions read on the OCP leaflet } \\
\hline Yes & I8I (80.I) & $95(79.2)$ & $7(87.5)$ \\
\hline No & $45(19.9)$ & $25(20.8)$ & I (I2.5) \\
\hline \multicolumn{4}{|c|}{ Perceived knowledge about OCP use } \\
\hline Strongly agree & $50(22.1)$ & $19(15.8)$ & I (I2.5) \\
\hline Agree & $64(28.3)$ & $40(33.3)$ & $2(25.0)$ \\
\hline Somewhat agree & $63(27.9)$ & $39(32.5)$ & $3(37.5)$ \\
\hline Not sure & $42(18.6)$ & $17(14.2)$ & $2(25.0)$ \\
\hline Not at all & $7(3.1)$ & $5(4.2)$ & $0(0.0)$ \\
\hline \multicolumn{4}{|l|}{ Regular use of OCP } \\
\hline Yes & $189(84.0)$ & $110(90.9)$ & $8(100.0)$ \\
\hline No & $36(16.0)$ & II (9.I) & $0(0.0)$ \\
\hline \multicolumn{4}{|c|}{ Perceived knowledge about missing one to two pills } \\
\hline Yes & $110(50.9)$ & $82(67.8)$ & $7(87.5)$ \\
\hline No & $70(32.4)$ & $15(12.4)$ & $0(0.0)$ \\
\hline Not sure & $36(16.7)$ & $24(19.8)$ & I (I2.5) \\
\hline \multicolumn{4}{|c|}{ Perceived knowledge about missing three or more pills } \\
\hline Yes & $35(16.1)$ & $27(22.5)$ & I (I2.5) \\
\hline No & $119(54.8)$ & $49(40.8)$ & $3(37.5)$ \\
\hline Not sure & $63(29.0)$ & $44(36.7)$ & $4(50.0)$ \\
\hline \multicolumn{4}{|l|}{ Age, years } \\
\hline$\leq 25$ & $30(13.2)$ & $18(14.9)$ & $3(37.5)$ \\
\hline $26-35$ & $120(52.6)$ & $62(5 \mid .2)$ & $3(37.5)$ \\
\hline $36-45$ & $69(30.3)$ & $39(32.2)$ & $2(25.0)$ \\
\hline$>45$ & $9(3.9)$ & $2(1.7)$ & $0(0.0)$ \\
\hline \multicolumn{4}{|l|}{ Ethnicity } \\
\hline Saudi & |3| (57.5) & $70(57.9)$ & $5(62.5)$ \\
\hline Non-Saudi & $97(42.5)$ & $51(42.1)$ & $3(37.5)$ \\
\hline \multicolumn{4}{|l|}{ Occupation } \\
\hline Housewife & I $88(82.5)$ & $92(76.0)$ & $7(87.5)$ \\
\hline Other & $40(17.5)$ & $29(24.0)$ & I (I2.5) \\
\hline \multicolumn{4}{|l|}{ Education } \\
\hline None & $19(8.3)$ & $2(1.7)$ & I (I2.5) \\
\hline Primary & $27(11.8)$ & $6(5.0)$ & I (I2.5) \\
\hline Secondary/High school & $120(52.6)$ & $67(55.4)$ & $2(25.0)$ \\
\hline Graduate/Postgraduate & $62(27.2)$ & $46(38.0)$ & $4(50.0)$ \\
\hline
\end{tabular}

Note: *Data are presented as frequency (percent) unless otherwise specified.

Abbreviations: OCP, oral contraceptive pill; SAR, Saudi riyals; USD, United States dollars. 
of the women reportedly knew they had to take an extra pill after missing one, in less than 12 hours.

In the current study, fewer women knew what to do after missing one or two pills than after missing three or more pills in a row. A similar finding was reported by Zapata et $\mathrm{al}^{19}$ who found evidence that more women knew what to do after missing one pill than after missing two or three pills (level I to level II-3) and knew what to do after missing two pills than after missing three pills (level II-3).

In the study by Al-Shaikh et al, ${ }^{9}$ it was reported that $13.5 \%$ of the women had knowledge about what to do in case of vomiting within 2 hours of taking an OCP. We found that a similar proportion of women in our study knew that another pill should be taken as soon as possible in the event of vomiting within 2 hours of taking an OCP. These findings also reveal that the women in this study have gaps in their knowledge about OCPs.

There are six oral contraceptive knowledge domains: use, side effects, risks, efficacy, mechanism of action, and assessment of benefits. ${ }^{20} \mathrm{We}$ attempted to assess users' knowledge from a perspective of method of use. As far as we are aware, this is the first study to have been conducted in a region of Saudi Arabia that has focused on the domain of method of use. From the perspective of method of use, we found that only $27.2 \%$ of women knew that OCPs could be started on any day of the cycle if pregnancy was excluded. We also found that half of the women were not aware that it was unnecessary to wait for withdrawal bleeding to occur before starting a new pack of OCPs. Furthermore, up to $63.9 \%$ of the women in this study had inadequate knowledge (score of $0-4)$ regarding OCP use, and only $2.2 \%$ had a satisfactory knowledge (score of $8-10$ ). This percentage is very low as compared with the $12 \%$ reported by other authors who conducted a study in 636 women attending 15 general practices in the south and west regions of England. ${ }^{21}$

\section{Limitations}

This study has some limitations that should be taken into consideration in future study designs. First, because this was a single-center hospital-based study, the findings cannot be extrapolated to the whole of Jeddah. Second, we did not address several knowledge domains, including the side effects, risks and efficacy, mechanism of action, and assessment of benefits of OCPs, as mentioned earlier. Importantly, our assessment of missed pills was weak, as we did not assess other misconceptions regarding OCP use or other plausible but incorrect answer choices. Third, our sample did not represent all educational and socioeconomic levels.
An equal representation of the study variables would have been beneficial in detecting an association between these variables and knowledge scores. Fourth, recruitment from a medical establishment biased the sample toward women who were more likely to seek medical attention and therefore received a prescription from a physician.

\section{Conclusion}

Women had large gaps in their knowledge about oral contraceptive use although they perceived the contrary. In particular, women lacked knowledge about what to do after missing more than two pills consecutively or vomiting within 2 hours of taking an OCP. They also lacked knowledge about withdrawal bleeding during OCP use. Importantly, and of future interest, are the possible gaps in patient education on oral contraceptive use, risks associated with their use, efficacy, and adverse effects. Since physicians, pharmacists, and nurses are the primary sources of information, it is of utmost importance that women's level of knowledge be assessed and that they eventually be counseled. In the same line, manufacturers of OCPs should make the information in package inserts easier and relevant to practical situations, so that women can understand instructions regarding missed pills or know what to do in the event of vomiting or diarrhea. We believe that such information would increase women's knowledge and consequently improve patient compliance. Finally, primary health care providers, including physicians, nurses, and pharmacists, have a responsibility to counsel patients so that they understand OCP instructions.

\section{Acknowledgments}

The authors would like to thank the medical students Dr Sarah Binmahfooz, Dr Zainab Alsadeq, Dr Sajeda Alsadah, Dr Deema Tashkandi, Dr Hanin Ayoub, Dr Nada Bashri, Dr Rawan Zatari, Dr Maram Ainalden, and Dr Alaa Albrakati for their efforts in helping with data collection. The authors would also like to acknowledege medical students Dr Majid Bahaa Abaalkhail and Dr Yousef Bahaa Abaalkhail for their help in data entry.

\section{Disclosure}

The authors declare no conflicts of interest in this work.

\section{References}

1. Allen K. Contraception - common issues and practical suggestions. Aust Fam Physician. 2012;41(10):770-772.

2. Trussell J. Contraceptive failure in the United States. Contraception. 2011;83(5):397-404

3. Marnach ML, Long ME, Casey PM. Current issues in contraception. Mayo Clin Proc. 2013;88(3):295-299. 
4. Al Sheeha M. Awareness and use of contraceptives among saudi women attending primary care centers in Al-qassim, saudi arabia. Int J Health Sci (Qassim). 2010;4(1):11-21.

5. Alsibiani SA. Use of misoprostol for self-induced medical abortions among Saudi women: a call for attention. Gynecol Obstet Invest. 2014;78(2):88-93.

6. Al-Turki HA. Contraception: attitudes and experiences of Saudi Arabian women. Health Care Women Int. 2011;32(2):134-139.

7. Peyman N, Oakley D. Married Iranian Women's Knowledge, Attitude and Sense of Self-efficacy about Oral Contraceptives: Focus Group Discussion. J Reprod Infertil. 2011;12(4):281-288.

8. Mahadeen AI, Khalil AO, Hamdan-Mansour AM, Sato T, Imoto A. Knowledge, attitudes and practices towards family planning among women in the rural southern region of Jordan. East Mediterr Health J. 2012;18(6):567-572.

9. Al-Shaikh GK, Mayet AY, Alshaikh MK, Hamad AF, Mahmoud MA, Aljadhey HS. Knowledge on adherence and safety of the oral contraceptive pill in Saudi women. Saudi Med J. 2012;33(6):665-670.

10. Ahmed S. Saudi parent's attitude and practice about self-medicating their children. Arch Pharm Pract. 2013;4:57-62.

11. Suleiman AK. Self-medication and the advisory role of pharmacists in Riyadh, Saudi Arabia. Arch Pharma Pract. 2013;4(4):180-185.

12. Al-Mansour R, Sabra AA, Hafez AS. Contraception: knowledge, attitudes and practice with special emphasis on contraceptive pills among Saudi Women at Al-Khobar City, Eastern Saudi Arabia. Egyptian Journal of Community Medicine. 2012:30(2). Available from http:// www.ejcm.eg.net/Pdf/2012/2/1.pdf.

13. Lwanga SK, Lemeshow S. Sample Size Determination in Health Studies: A Practical Manual. Geneva: World Health Organization (WHO); 1991. Available from: http://whqlibdoc.who.int/ publications/9241544058_\%28p1-p22\%29.pdf. Accessed October 29, 2014.

14. WHO Department of Reproductive Health and Research, John Hopkins Bloomberg School of Public Health Center for Communication Programs Knowledge for Health Project. Family Planning: A Global Handbook for Providers. Update 2011. Baltimore and Geneva: CCP and WHO; 2011. Available from: http://whqlibdoc. who.int/publications/2011/9780978856373_eng.pdf?ua=1. Accessed October 29, 2014.
15. Chebaro R, El Tayyara L, Ghazzawi F, Abi Saleh B. [Knowledge, attitudes and practices about contraception in an urban population.] East Mediterr Health J. 2005;11(4):573-585. French.

16. Frost JJ, Darroch JE, Remez L. Improving contraceptive use in the United States. In Brief. 2008:1. Available from: www.guttmacher. org/pubs/2008/05/09/ImprovingContraceptiveUse.pdf. Accessed November 3, 2014.

17. Dardano KL, Burkman RT. Clinical aspects of oral contraceptive use. In: Bloomer DG, editor in chief. Global Library of Women's Medicine [online]. London: Foundation for The Global Library of Women's Medicine; nd [updated Sep 2008]. Available from: http://www.glowm. com/section_view/heading/Clinical\%20Aspects\%20of\%20Oral\%20 Contraceptive\%20Use/item/391. Accessed November 3, 2014.

18. Hamani Y, Sciaki-Tamir Y, Deri-Hasid R, Miller-Pogrund T, Milwidsky A, Haimov-Kochman R. Misconceptions about oral contraception pills among adolescents and physicians. Hum Reprod. 2007;22(12):3078-3083.

19. Zapata LB, Steenland MW, Brahmi D, Marchbanks PA, Curtis KM. Patient understanding of oral contraceptive pill instructions related to missed pills: a systematic review. Contraception. 2013;87(5):674-684.

20. Hatcher RA, Trussell J, Nelson AL, Cates W Jr, Stewart FH, Kowal D, editors. Contraceptive Technology. 18th ed. New York, NY: Ardent Media; 2004.

21. Little P, Griffin S, Kelly J, Dickson N, Sadler C. Effect of educational leaflets and questions on knowledge of contraception in women taking the combined contraceptive pill: randomised controlled trial. BMJ. 1998; 316(7149):1948-1952. 


\section{Supplementary material \\ Questionnaire used in the study}

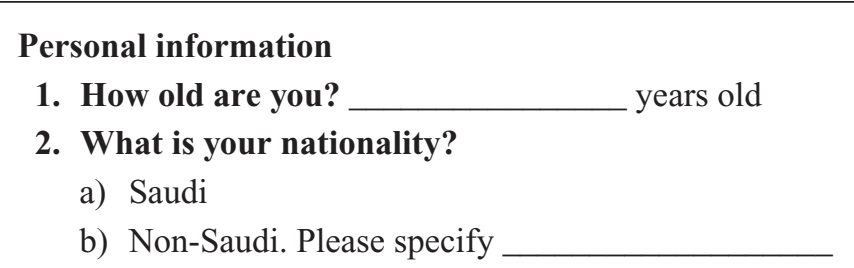

3. What is your highest level of education?
1) None
2) Primary school
3) Secondary
4) High school
5) University/Graduate
6) Postgraduate

4. What is your occupation?
1) Housewife
2) Teacher
3) Doctor
4) Nurse
5) Office job
6) Self-employed
7) Other (please specify)

5. What is the monthly income of your family (household)?
1) Less than SAR 5,000
2) Between SAR5,000 and 10,000
3) Between SAR10,000 and 15,000
4) Between SAR15,000 and 20,000
5) Greater than SAR 20,000

Obstetric history

6. How long have you been married? years

7. Have you ever been pregnant? Consider terminated pregnancies (abortion/miscarriage)
a) Yes, time(s) (in total)
b) No

8. Number of miscarriages/abortions:

9. Do you have children?
1) Yes
2) No

10. If yes then how many children do you have?

Family planning method used

11. For how long have you been using the oral contraceptive pill? ___ years,
12. How did you select this method of contraception (oral contraceptive pill)?
1) Advised by your general physician
2) Advised by your gynecologist
3) Self-medication
4) Other
5) Don't remember 
13. Were you given instructions about the method of using pills by your doctor?
a) Yes
b) No
c) Not sure
d) Oral contraceptive pill not prescribed by a doctor

14. Did you read the pill package insert?
1) Yes
2) No

15. Do you think that you have adequate knowledge about the correct use of pills?
1) Strongly agree
2) Agree
3) Somewhat agree
4) Not sure
5) Not at all

Knowledge about starting the oral contraceptive pill

The following statements are about the use of contraceptive methods.

What do you think? Are the statements correct (C), incorrect (I), or 'I don't know' (?)

16. The oral contraceptive pill is the most reliable contraceptive method

17. In case of vomiting within 2 hours of taking an oral contraceptive pill, another pill should be taken as soon as possible

Which of the following is correct?

18. An oral contraceptive pill can be started any day of the cycle if the woman is sure that she is not pregnant
1) Correct
2) Incorrect
3) Don't know

19. Additional contraception is required when an oral contraceptive pill is started after the 5 th day of the cycle
1) Correct
2) Incorrect
3) Don't know

20. You must wait for withdrawal bleeding to start the new pack
1) Correct
2) Incorrect
3) Don't know

Knowledge about oral contraceptive pill use

21. Do you use oral contraception as recommended?
1) Yes
2) No

22. How many days a month on average have you missed your pill? days

23. Do you know what should be done if you forget one or two pills?
1) Yes
2) No
3) Not sure

If the response to question 22 is yes/unsure then ask:

24. What should be done if you forget one to two pills?

1) Take pill as soon as you remember and take the scheduled medicine as well, even if it means taking two pills in 1 day

2) Other response

3) Don't know

25. Do you know what should be done if you forget three or more pills in a row?
1) Yes
2) $\mathrm{No}$
3) Not sure 
If the response to question 25 is yes/unsure then ask:

What should be done if you forget three or more pills?

Which statements are correct (C), incorrect (I), don't know (?)

26. Take the last pill you missed as soon as you remember

27. Continue taking the rest of the pack as usual

28. Use an additional method of contraception for the next 7 days

29. If three or more pills are missed in the 3rd week, a new pack should be started after finishing the pack without a 7-day pill-free interval

\section{Publish your work in this journal}

Patient Preference and Adherence is an international, peer-reviewed, open access journal that focuses on the growing importance of patient preference and adherence throughout the therapeutic continuum. Patient satisfaction, acceptability, quality of life, compliance, persistence and their role in developing new therapeutic modalities and compounds to optimize clinical outcomes for existing disease states are major areas of interest for the journal. This journal has been accepted for indexing on PubMed Central The manuscript management system is completely online and includes a very quick and fair peer-review system, which is all easy to use. Visit http://www. dovepress.com/testimonials.php to read real quotes from published authors.

\footnotetext{
Submit your manuscript here: http://www.dovepress.com/patient-preference-and-adherence-journal
} 